\title{
LAS MEDIDAS DE LOS TRAZADOS ORTOGONALES
}

Joaquín SABATÉ BEL

Muchas de las ciudades que conocemos tienen su origen o un proyecto de extensión posterior basado en un trazado regular. Constituyen una de las formas de crecimiento urbano más común y afortunadamente utilizadas y la diversidad de soluciones a que ha dado lugar enriquecen los tratados de historia del urbanismo. Parcelas, tipos edificatorios, calles y avenidas, y manzanas de diferentes tamaños, se combinan en propuestas ricas y diversas, donde la única característica común parece ser la utilización de una trama rectangular, con la consiguiente racionalidad, seriación, capacidad de extensión y transformación.

En este texto analizamos esencialmente la forma y medidas de estos proyectos (tamaño calle, anchura y profundidad de la manzana, superficie de la misma, extensión global), al objeto de verificar si existen ciertas constantes en estas dimensiones, o bien relaciones significativas entre las mismas, medidas más adecuadas que otras, en esta forma de hacer ciudad, que la hagan más funcional, más económica o más bella.

Buenas medidas urbanas, ancho calle, profundidad manzana, superficie módulo.

\section{THE MEASUREMENT OF ORTHOGONAL CITY LAYOUTS}

Many of the cities we know have their origin or subsequent extension project based on a regular layout. This is one of the most common and fortunately used urban growth patterns and the diversity of solutions that has given rise enriches the town planning history treatises. Plots, building typologies, streets, avenues, and blocks of different sizes, are combined in rich and diverse proposals, where the only common feature seems to be the use of a rectangular layout, with the consequent rationality, serialization, extension and transformation capacity.

In this paper we analyse essentially the shape and measures of these projects (street size, width and depth of the block, its surface and the total extension), in order to verify if there are certain constants among these dimensions, or significant relationships between them, perhaps more appropriate measures, in order to built a more functional, cheaper or beautiful city.

Good city measurements, street width, block depth, module area.
La construcción o extensión de ciudades en base a trazados ortogonales constituyen una de las formas de crecimiento urbano más común y afortunadamente utilizadas. Las razones para ello están sin duda en sus singulares características ${ }^{1}$.

a) Se trata de proyectos que utilizan una trama rectangular, lo que supone atributos de racionalidad, seriación, capacidad de extensión y transformación.

b) Tienen un doble carácter, unitario y fragmentario en su proceso de transformación, lo que agiliza su implementación y gestión.

Es unitario en la medida en que existen unas reglas de juego claras, un trazado en planta que define calles y plazas (terreno público) y manzanas (terreno sujeto a aprovechamiento privado), así como unas reglas que definen la forma de las construcciones (ordenanzas o normas). Tras una actuación inicial de la administración pública, que define la ordenación (trazado, o sea, alineación, y reglas de las construcciones), los diferentes agentes que participan en la construcción de la ciudad, saben a qué atenerse, y pueden levantar sus edificios, sin necesidad de esperar a que lo hagan sus vecinos.

Es fragmentario, porque estos diversos agentes pueden ir actuando con cierta independencia, en la localización de sus construcciones, en los ritmos de su ejecución, en los volúmenes y tipologías edificatorias. Un conjunto de pequeñas decisiones, la mayoría privadas, completa y da sentido a la inicial ordenación de carácter público.

c) Se dan asimismo ventajas de carácter socioeconómico. Los grandes ensanches tienen éxito con las nuevas corrientes liberales del siglo XIX, con el

1 La investigación que da pie a este texto tiene un origen lejano. Arranca de unas notas en una libreta que Manuel de Solá-Morales me enseña a mediados de 1977 . Éstas recogen las medidas de unas pocas ciudades y junto con algunas sugerencias de Manuel, dan pie al inicio de un estudio de las medidas de cerca de doscientos proyectos de ciudades con trazados regulares que, cual río Guadiana que emerge y desaparece, he ido desarrollando intermitentemente a lo largo de más de treinta años. Parte de los cálculos y algunos primeros dibujos tentativos, también de Rosa Barba, dan soporte a una conocida carta "QQuerido León, ¿ipor qué 22 × 22 ?", en Arquitecturas Bis, número 20, paginas 7-12, 1978), que Manuel envia a Leôn Krier, en respuesta a una provocadora propuesta de este ultimo, donde fragmenta en dieciséis pabellones la vol

Utilizamos la denominación trazados para englobar cuadrículas (que prestan escasa atención al viario y mayor a la división del suelo en solares), mallas, que recogerian aquellas propuestas que ponen el énfasis en el viario, y los caracteristicos Ensanches decimonónicos, que buscan un cierto equilibrio entre ambas opciones. Este estudio, aún en curso, y del que aquí se resumen algunas conclusiones, siempre provisionales, tiene un objetivo fundamental: reflexionar en torno a las medidas de un buen número de ciudades de trazados regulares,. Y rinde, por supuesto, tributo a las sugerencias iniciales y a las enseñanzas continuas de un gran maestro. En esta última etapa he contado con la inestimable ayuda de las arquitectas Melisa Pesoa y Laia Vilaubí. 
empuje de una burguesía, industrial o comercial, pero esencialmente ilustrada. La consolidación de esta nueva clase social da sentido a una nueva idea de ciudad; al igual que a nuevas relaciones sociales. Son cuestiones que en nuestro país van aparejadas, y que dan pie a la aparición de nuevos agentes urbanos y de nuevas tipologías arquitectónicas, como la casa de renta.

Pero no son los ensanches el único proyecto de ciudad basado en trazados regulares. Desde tiempos remotos encontramos numerosas propuestas. Éstas proliferan en determinados momentos, en el Medievo, y particularmente en los procesos de Reconquista (bastidas, poblas y fundaciones); en el espectacular episodio de construcción de nuevas ciudades durante los siglos XVI y XVII, tanto en América Latina, como en Norteamérica; durante el barroco; con los grandes ensanches decimonónicos, o con la urbanización vinculada al ferrocarril o a los grandes proyectos de poblamiento de la segunda mitad del siglo XIX. En nuestra investigación, tanto la fundación de nuevas ciudades, como las propuestas para su crecimiento, o los ensanches, se examinan esencialmente desde la forma y medidas de su proyecto. Se interpretan en tanto que trazados (malla de calles y cuadrícula de edificios) con una forma rectangular y con unas dimensiones concretas (tamaño calle, anchura y profundidad de la manzana, superficie de la misma, extensión global...).

Pero conviene remarcar que se trata de dimensiones variables a lo largo del tiempo y dependientes a su vez de tradiciones y contextos geográficos y culturales bien diversos. Ello nos lleva a plantear algunas preguntas, como:

¿Existen ciertas constantes en estas medidas?

¿Ciertos ámbitos donde tiendan a concentrarse?

¿Existen relaciones significativas entre las mismas?

¿Cabe encontrar ciertas medidas más adecuadas que otras, en esta forma de hacer ciudad, que la hagan más funcional, más económica o más bella?

Antes de intentar responder a estas cuestiones conviene tener bien presente que:

a) Las diferentes medidas (calle-fondo-superficie) son mucho más que cifras abstractas, que simples relaciones geométricas. En la combinación de las diferentes dimensiones cabe reconocer ideas de sección de calle, de tipo edificatorio, de capacidad de gestión... en definitiva, ideas de ciudad, bien diferentes.

b) Esta pretensión de descubrir las proporciones más adecuadas entre las par tes de un proyecto se ha planteado repetidamente en el campo de la arquitectura y el urbanismo. A lo largo de la historia numerosos estudiosos buscan en esta estrecha relación, en la descomposición matemático-geométrica de los proyectos, un ideal de dimensionado ajustado de las partes, al objeto de componer el todo según reglas bien precisas. Esta búsqueda está a la base de diversos estudios sobre los órdenes clásicos, pero asimismo sobre la forma de las ciudades, recogidos en numerosos artículos, por ejemplo en la revista Enviromental Planning. ${ }^{2}$

Los estudios sobre las buenas medidas de las partes se producen no tan solo en el campo del proyecto edificatorio, sino en el de la construcción de ciudades, en sucesivas momentos y culturas, desde los comentarios de Platón en la República a las Leyes de Indias, pasando, en el caso español por varios tratados medievales. ${ }^{3}$

Pero además la construcción de ciudades en cuadrícula es un campo de experimentación riquísimo desde tiempos inmemoriales. Por ello no importa tanto discutir la paternidad original de dicha opción (en China o Mesopotamia encontramos propuestas antiquísimas), sino recordar, como nos dice Gabriel Alomar, "...que la ciudad nace cuadriculada". ${ }^{4}$

Esta regularidad geométrica de las ciudades hace fortuna en la Grecia Clásica (Mileto, Priene), de donde toma después el nombre de trazado hipodámico. Pero se utiliza asimismo en los campamentos romanos, en las nuevas ciudades del camino de Santiago en el siglo décimo, en las bastidas francesas en el siglo XIII, en las villas nuevas y ciudades de reconquista en la Espańa de los siglos catorce y quince, o en las poblas mallorquinas del siglo XIV. ${ }^{5}$

Evidentemente esta tradición de trazados regulares alcanza un punto álgido en la magna obra de fundación de ciudades en América Latina desde principios del siglo XVI hasta finales del XVIII. Y se repite en la fundación de más de un centenar de ciudades en la provincia de Buenos Aires en la siguiente centuria, o de tantas otras levantadas al amparo de los trazados del ferrocarril o de la colonización en Norteamérica.

Antes, con los proyectos de Ensanches del XVIII y el XIX se vuelve a plantear (a una nueva escala) la discusión de las medidas más adecuadas de calles y manzanas. Los mismos estudios de Ildefonso Cerdá para el Ensanche de Barcelona evidencian esta preocupación. ${ }^{6}$

2 Particularmente en la etapa en que dicha revista es dirigida por Lionel March. En la serie B se discuten en varias ocasiones este tipo de temas.

3 "De cómo debe ser aposentada la hueste" de Alfonso X el Sabio; Ordinacions del rey Jaime Il; el "Regiment de príncipes e de les ciutats e de la casa pública" de Francesc de Eiximenis, o."de quina forma deu haver ciutat bella e ben edificada". 4 Gabriel Alomar Esteve. Urbanismo regional en la Edad Media: Las "Ordinacions" de Jaime II (1300) en el Reino de Mallorca. Gustavo Gili, Barcelona, 1976.

5 Ver en la obra de Gabriel Alomar, como precisamente las poblas en Mallorca constituyen un ejemplo bien singular de fundación, donde ya se defienden, mediante las Ordinacions, unas medidas muy especificas de la calle (6,32 metros) $y$ de las manzanas $(42 \times 42$ metros).

6 En muchas ocasiones se ha cuestionado si Cerdà se preocupa excesivamente por la separación entre cruces, si desatiende al tamaño de la manzana y de la arquitectura, o si propone calles muy amplias para su tiempo, o plantea una propuesta
muy o poco pública. Todo ello nace de decisiones fundamentales del proyecto i Cuán diferente hubiera sido Barcelona con manzanas de $60 \times 60$ o de $200 \times 400$ metros, como Petra o Berlíi, o de $105 \times 105$ metros, como Buenos Aires? Hoy sabemos que la particular decisión de Cerdà (manzanas de $113 \times 113$ metros) obedece a un curioso y riguroso cáculo donde dadas algunas variables fijas, ancladas en la tradición constructiva, el autor del proyecto de Ensanche de Barcelona deduce aquella medida que optimiza la habitabilidad de las viviendas. 
Los tratadistas alemanes de finales del siglo XIX formulan de manera bien precisa la discusión sobre la forma y dimensiones de los trazados. Encontramos todo un conjunto de textos (en artículos o capítulos de libros) con un enunciado similar, que tratan en definitiva de “...la forma más adecuada y la profundidad más lógica de las manzanas desde el punto de vista de la economía y la higiene....". Constituyen un argumento central para autores como Joseph Stübben, Reinhard Baumeister, Rud Eberstadt y tantos otros..., y llenan páginas y páginas de la revista "Der Städtebau. En ellas se comparan, diferentes soluciones de manzanas y parcelas (cuadradas-hexagonales-triangulares-rectangulares), clasificadas según criterios de ventilación, aprovechamiento edificatorio, facilidad de descomposición o cantidad de fachada. A los estudios realizados según ópticas (económicas, sanitarias, edificatorias) para encontrar las medidas más adecuadas de las manzanas, se unen los de secciones de calles y cruces, en los textos de los tratadistas de finales de siglo XIX. Todo ello contribuye a verificar, cuanto forma y dimensión de calles y manzanas, y contenido edificatorio, tipo de casa y de ciudad guardan relaciones bien precisas.

Y si eso es así, y si logramos desvelar estas medidas, el buen proyecto de ciudad consistiría, ni más ni menos, que en tomar bien las medidas, como en casa del sastre.

Para responder por tanto a las preguntas antes formuladas sobre las buenas medidas de la ciudad, hemos analizado dos centenares de casos, que incluyen no tan solo los ensanches de los siglos dieciocho y diecinueve, sino asimismo ejemplos bien representativos de otros muchos proyectos previos y posteriores, que toman el trazado rectangular como base, entre ellos los poblados de colonización (en Francia y en la Península Ibérica a lo largo de los siglos previos), las grandes fundaciones de ciudades de tradición española, francesa o inglesa, desde el siglo XVI al XIX, o las ciudades de fundación del Renacimiento y el Barroco hasta el siglo XVIII.

Un primer análisis se centró en tres medidas básicas, con las que se pueden relacionar muchas otras:

a) La anchura de la calle (a), como idea de circulación y capacidad de la malla viaria

b) La profundidad de la manzana (l), o sea, el lado menor del rectángulo, por su contribución en decidir la profundidad edificable (en uno, o los do frentes), y por tanto incidir en el tipo de construcción y en la posibilidad de usos diversos.

c) El tamańo del módulo (manzana + semi-calles que la rodean), como idea de la escala de actuación, de la ambición del proyectista o del gobernante, de su capacidad de construir ciudad.

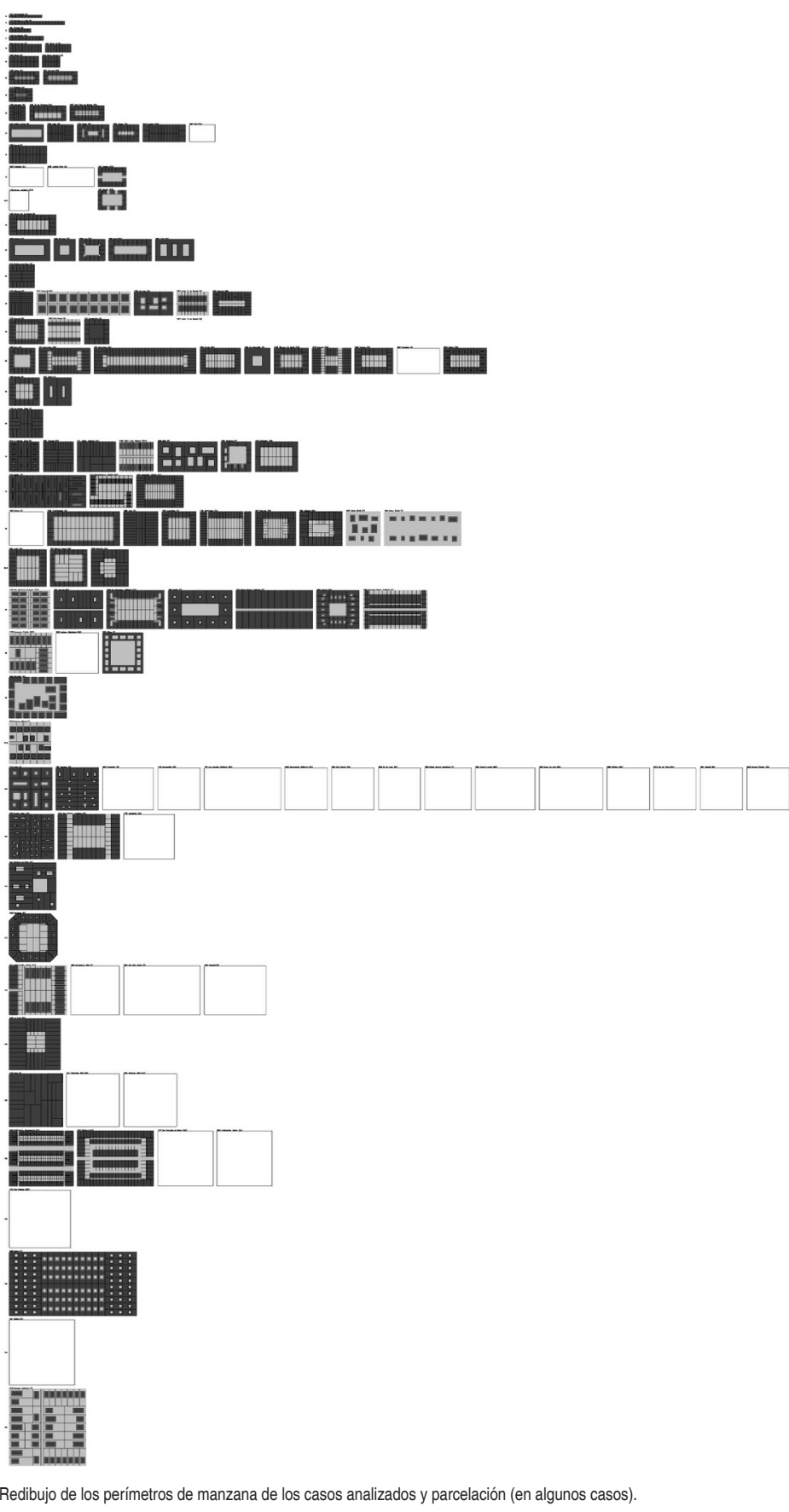




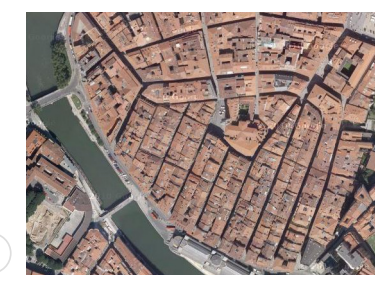
Bilbao, Spain

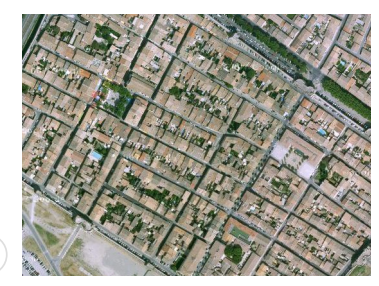

Aiguesmortes, France

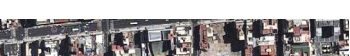

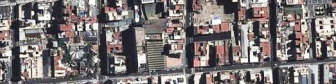

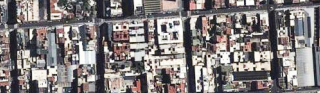

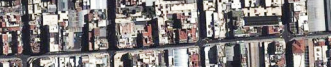

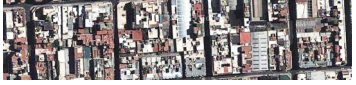
Buenos Aires, Argentina

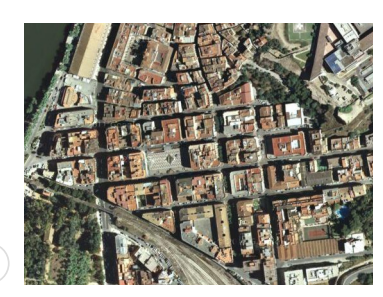

Tortosa, Spain

EM

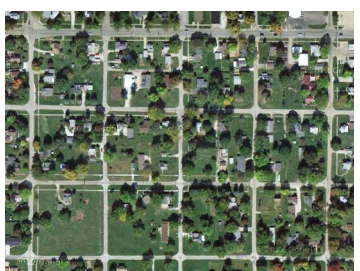

Galva, Illinois

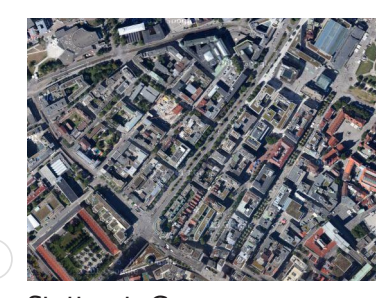

Stuttgart, Germany M

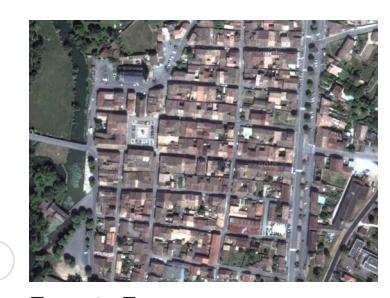

Eymet, France

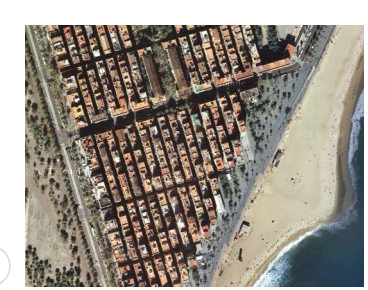

Barceloneta, Spain

$\mathrm{Br}$

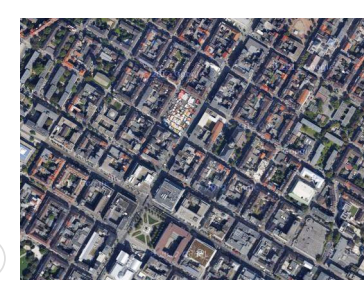

Mannheim, Germany

EM

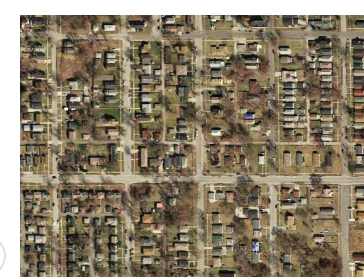

Gary, Indiana

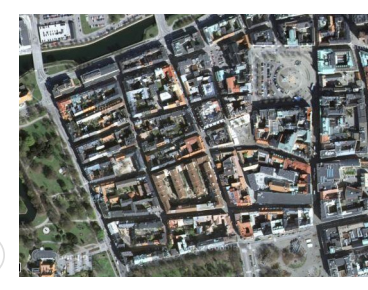

Malmö, Sweden

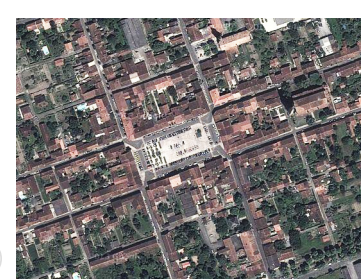

Marciac, France

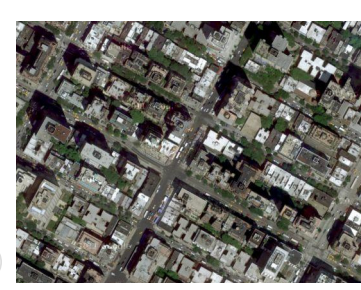

Manhattan, New York

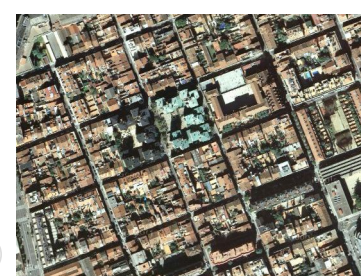

Sabadell, Spain

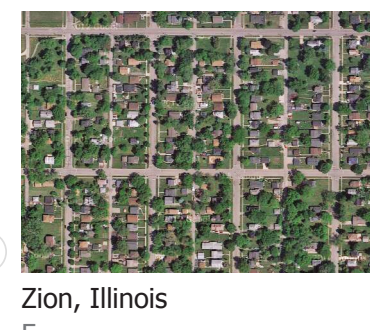

1

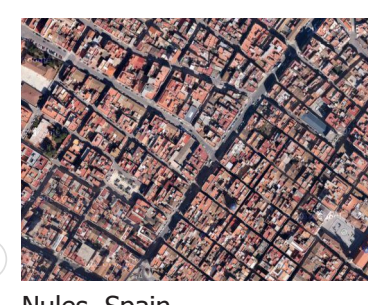

Nules, Spain

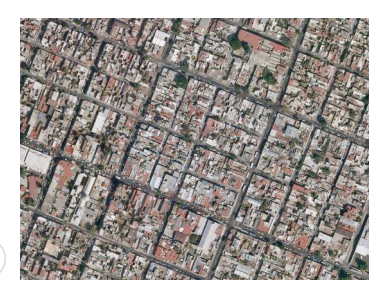

Guadalajara, Mexico

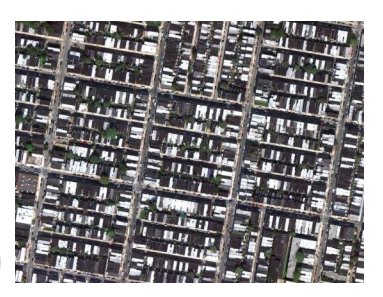

Philadelphia, Pennsylvania

CU

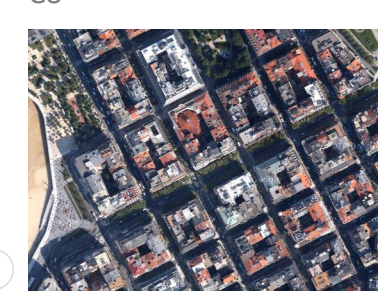

San Sebastián, Spain

27)

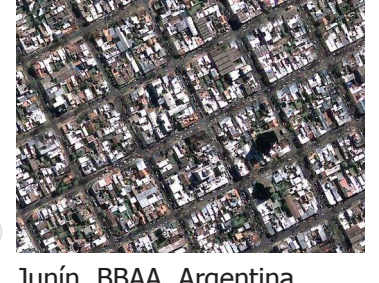

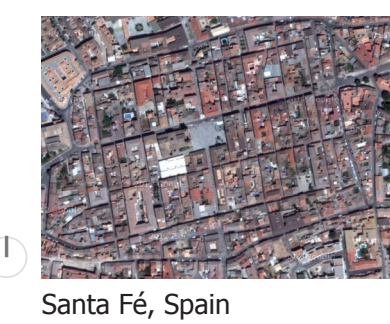

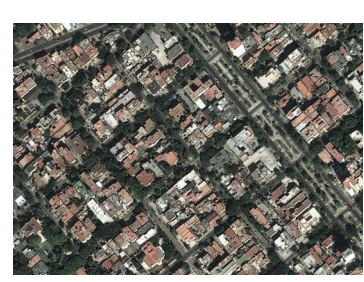

La Habana, Cuba

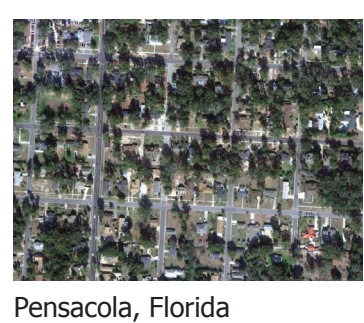

CUE

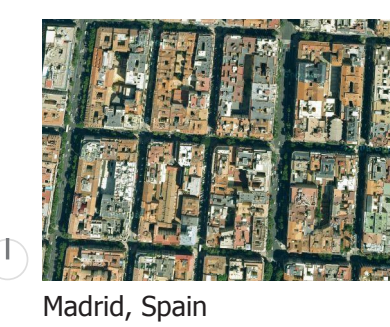

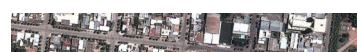

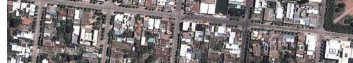

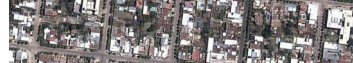
bf

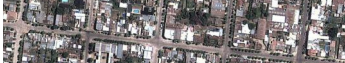

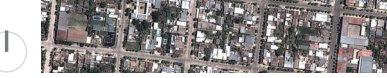
25 de mayo BBAA, Argentina BA
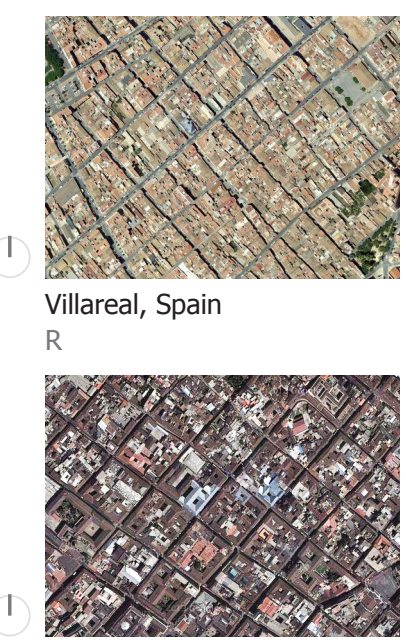

Quito, Ecuador

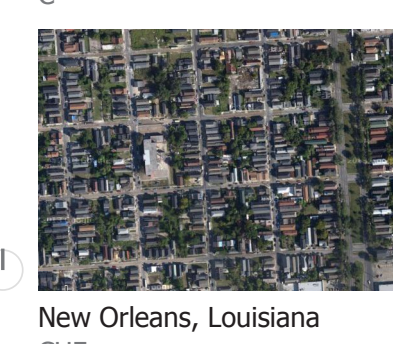

CUF

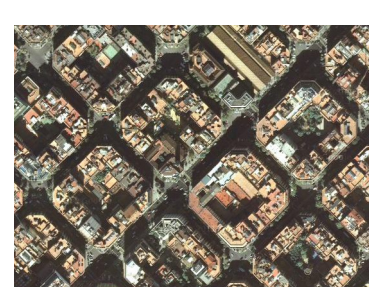

Barcelona, Spain

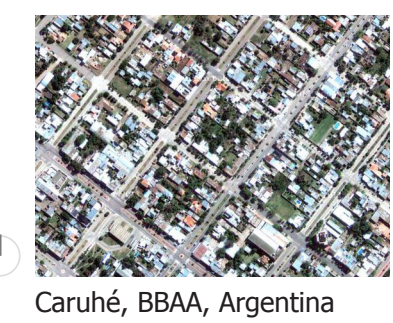


En definitiva se trata de aproximarnos a las medidas de una cierta idea de calle, de arquitectura y de ciudad.

Veamos a continuación unos primeros resultados de esta investigación.

\section{Anchura de la calle}

El cuadro de anchos de calle nos ofrece una primera idea de la capacidad de la malla viaria, de su ajuste a la circulación, pero asimismo del escenario de la arquitectura, de los accesos y servicios.

La mayor parte de las ciudades analizadas tienen calles con una anchura que oscila entre los 8 y los 20 metros, con menos del $20 \%$ de casos con anchuras inferiores o del $10 \%$ superiores a dicho intervalo. Los primeros se corresponden con proyectos más antiguos, de pequeńas ciudades levantadas durante el proceso de la Reconquista, fundaciones barrocas, o ensanches menores del siglo XIX. Existen asimismo un número similar de proyectos, la anchura de cuyas calles supera los veinte metros. Son apenas dos casos europeos (Edimburgo y Glasgow), siendo el resto ciudades norteamericanas, levantadas muchas de ellas al amparo de la "fiebre del ferrocarril", o alguna gran capital latinoamericana (extensión de Buenos Aires, Concepción o El Callao).

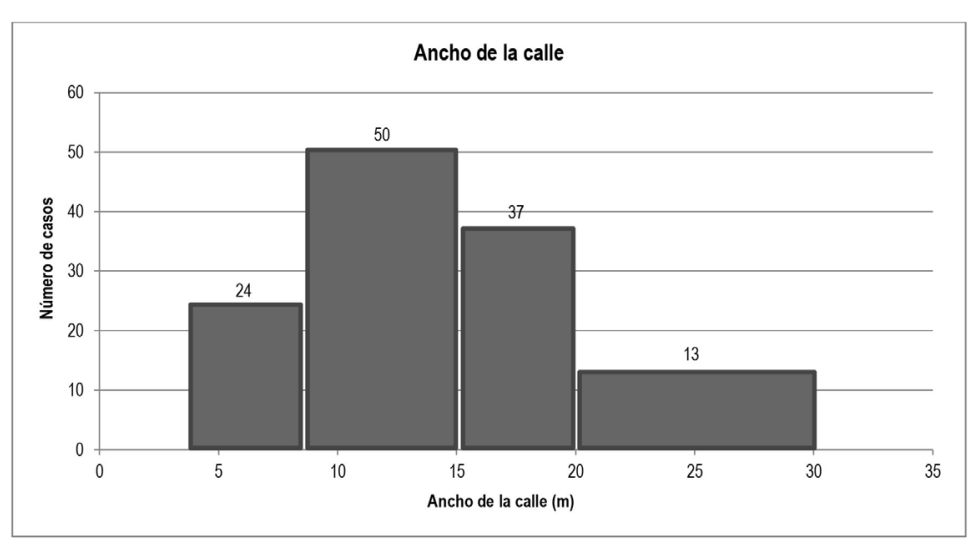

La oscilación en este parámetro es relativamente ajustada, entre los 4 metros de Nules y los 30 metros de anchura en Indianápolis, Santa Mónica, Montezuma, o las citadas Edimburgo y Glasgow.

Parece razonable esperar una tendencia al incremento de la anchura a lo largo del tiempo. Sin embargo al observar el gráfico, descubrimos una relativa irregularidad en dicha evolución, dentro de, efectivamente, una tendencia general a dicho incremento. Ésta parece clara solo hasta mitad del siglo XVIII (en Edimburgo la calle alcanza en 1767 una anchura de 30 metros), el incremento de anchura se interrumpe después, y los valores se concentran mayormente entre los quince y los veinte metros, con apenas un $10 \%$ del total de excepciones por debajo (los denominados Ensanches menores en Cataluña y Espańa y algunos proyectos barrocos), $\mathrm{y}$ apenas cuatro por arriba (las ciudades antes mencionadas).

Este aumento de la anchura de la calle tiene que ver con el incremento de los movimientos de personas y carruajes, aunque no resulta una simple consecuencia de esta mayor circulación. Las primeros proyectos, generalmente fundaciones, como las bastidas, o pequeńas extensiones (Malmoe, Aigües Mortes, Carcassone, Monpanzier, Aix en Provence, Villarreal, Petra, Stuttgart...), interpretan la calle como una simple garantía de acceso, sea cual sea su dimensión, por el simple hecho de su existencia. No existe aún, como tal, un proyecto específico de calle. Ésta se entiende esencialmente como una reserva de paso.

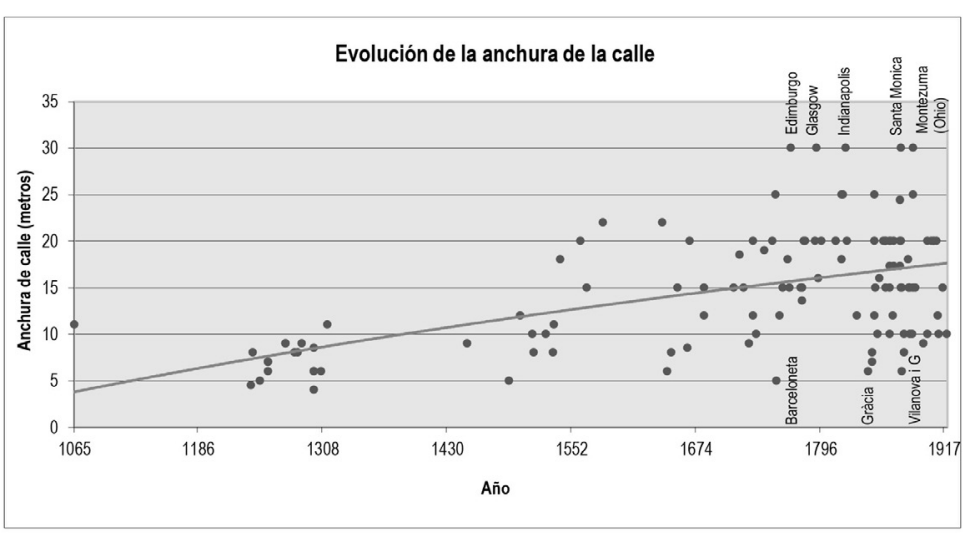

Posteriormente, ya a partir del siglo XVII, la calle en los ejemplos estudiados se nos muestra como canal de acceso y eje de relación. La calle se proyecta al igual que se diseñan las casas. Se convierte en el espacio público por excelencia, en el escenario urbano. La calle pasa a ser materia de arquitectura y muchas ciudades a proyectarse desde la idea de calle.

En diversas propuestas la calle deviene un elemento básico, cuando no el fundamental, en la propuesta de la ciudad, en el dimensionado de conjunto urbano. Aumenta su medida, gana en protagonismo vinculada a nuevos requerimientos, a la especialización del tráfico, a la disposición de los servicios, a ser el escenario en el que mostrar la nueva arquitectura. La calle pasa a ser un tema de proyecto con contenido propio. Se diseńan sus elementos, aceras, calzadas, árboles, farolas, mobiliario urbano. Empiezan a proliferar los manuales con perfiles (Cerdá, Henard...). Y 
de éstos pasamos a los textos de Stübben y Unwin, donde adquiere un notable protagonismo.

La calle adquiere una configuración espacial precisa, una lógica propia como base de la circulación, los servicios y la arquitectura. Dicho de forma sintética, en la colonización se impone el orden del suelo y la calle se plantea como una simple reserva de paso; en el barroco el orden de la arquitectura da medida a los trazados. Más adelante, ya avanzado el siglo XIX, las exigencias de los servicios y la circulación (el tráfico de vehículos y el movimiento de las personas, los nuevos usos comerciales) son quienes dan medida a las calles.

\section{Tamańo del lado menor de la manzana}

Escogemos este parámetro (profundidad o lado menor de la manzana), toda vez que tiene un estrecho vínculo con la posible opción tipológica o la compatibilidad de determinados usos. La profundidad de la manzana incide en la disposición de los frentes en uno o ambos lados de la misma. El fondo edificable da lugar a la aparición, o no, de un patio central, o determina la necesidad, con el aumento de su dimensión, de otros patios de ventilación.

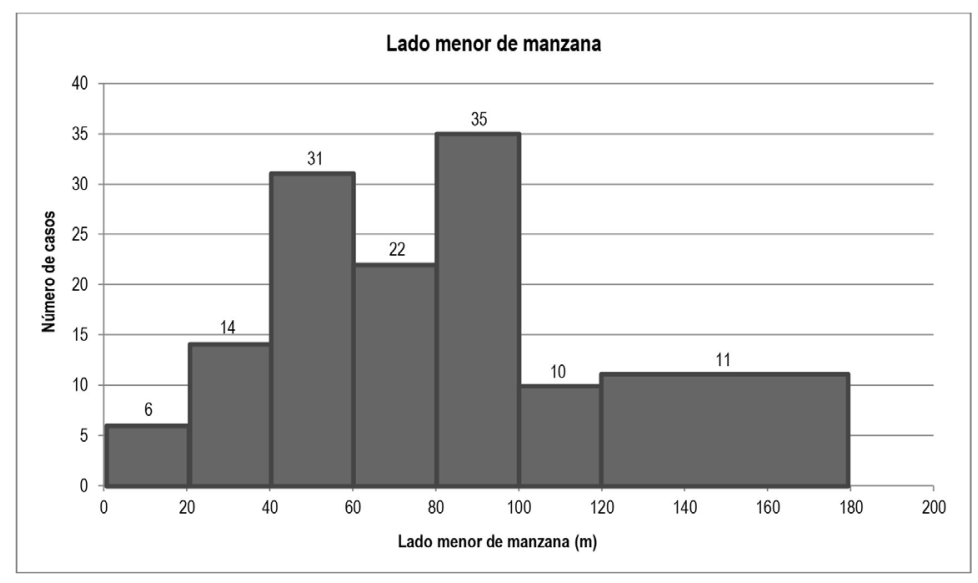

Entre las ciudades analizadas apenas un 5\% tiene manzanas con profundidades inferiores a 20 metros o un $10 \%$ superiores a 120 . Pero el reparto en franjas de 20 metros dentro de dicho intervalo, es relativamente homogéneo, predominando al inicio profundidades hasta 60 metros, y más adelante entre 80 y 100 metros. Y sin embargo pareciera que profundidades entre los 60 y 80 metros, son las que ofrecen opciones más razonables de profundidades edificables en ambos lados de la manzana entre 15 y 20 metros y un patio central con suficiente holgura, y, en conjunto, un buen aprovechamiento global. Pero como verificamos son más frecuentes aquellos grupos con profundidades entre 40 y 60 , y 80 y 100. Con tamaños mayores o bien existe una notable desproporción entre la profundidad y el aprovechamiento edificable (Edimburgo), o la manzana se ocupa muy densamente, como en grandes ciudades latinoamericanas (Buenos Aires y Lima), pero asimismo en la propuesta de Hobrecht para Berlín.

Resulta llamativa la oscilación tan considerable de las medidas de este parámetro, desde la escasísima profundidad de las bastidas francesas, o los menos de 9 metros de la Barceloneta, hasta los más de 100 metros de fondo. Destacan por encima numerosas capitales latinoamericanas (Quito, Mendoza, Concepción, Buenos Aires, Guatemala y Santiago de Chile, entre 100 y 110 metros de fondo), o incluso otras con profundidades muy superiores (La Plata, Lima y Callao). Llama asimismo la atención el gran tamaño, quizás por emulación de su capital, de las singulares fundaciones decimonónicas en la provincia de Buenos Aires. Destacan asimismo algunos ensanches de ciudades españolas (Barcelona y Valencia). Pero los mayores tamańos se alcanzan en las ciudades fundadas en el proceso de colonización del Oeste norteamericano, acompañando el ferrocarril (entre 115 y 130 metros) y en los casos singulares de Berlín y Edimburgo.

En cuanto al fondo de la manzana, existe una clara tendencia a aumentar con el tiempo, con contadas y singulares excepciones. Esta tendencia esta vinculada sin duda al incremento de profundidad edificable con la aparición de los patios de ventilación. Pero dicha tendencia se desacelera, o incluso se invierte, desde mediados del siglo XIX.

Veamos algunos ejemplos. Entre los de menor profundidad encontramos la Barceloneta, un proyecto de 1753 con viviendas pasantes de menos de nueve metros de fondo, calles de seis metros de ancho y una altura reducida de las viviendas, lo que redunda en una relación inicial muy ajustada. En Aix en Provence un fondo de 30 metros da lugar ya a doblar las construcciones a ambos lados, con 12 metros de profundidad edificable (y soluciones bien racionales de viviendas pasantes), pero un patio central de escasa anchura, de apenas seis metros. En Edimburgo, en cambio, se disponen en cada lado sobre 130 metros de fondo de manzana, dos cuerpos principales y dos auxiliares de escaso fondo. Ello redunda, como veremos después, en un grado de aprovechamiento muy bajo.

Al igual que hicimos al analizar la sección de la calle, descubrimos, también aquí, diferentes familias de comportamientos.

En un primer grupo encontramos aquellos casos donde se tiende a ocupa densamente la manzana. Entre éstos, Aranjuez es un ejemplo muy intere- 
sante, por la disposición bien regular de edificios de dos crujías (a la calle y al patio) y un cuerpo al fondo de éste, con otra crujía más. En la mayor parte de las grandes ciudades de fundación en Latinoamérica (Santiago de Chile, Buenos Aires, Córdoba o Mendoza), la inicial ocupación discreta de la "cuadra", con casas-patio, o construcciones alineadas de escasa profundidad, se incrementa notablemente durante los dos últimos siglos. En Berlín esta ocupación intensa adquiere un carácter paradigmático. Dada la considerable profundidad de la manzana (muy por encima de los cien metros), y al objeto de maximizar el rendimiento edificable, ésta se ocupa intensamente, dejando apenas unos mínimos patios de ventilación.

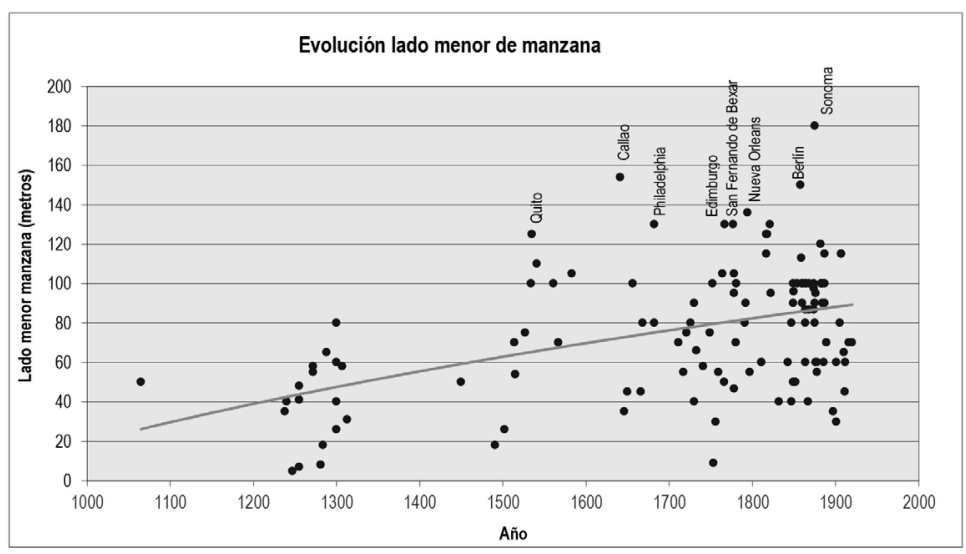

Un segundo grupo estaría conformado por ciudades con tamaños grandes asimismo del fondo de las manzanas. Pero en este caso, en lugar de ocuparlas densamente, vemos como disponen generosos patios centrales y soluciones bien singulares en las esquinas. Barcelona sería en este sentido un caso bien representativo.

Durante mucho tiempo la medida del fondo o lado menor de la manzana, guarda una estrecha correlación con la tipología edificatoria. En este sentido la longitud o lado mayor de dicha manzana, es relativamente menos relevante; en función de su medida se dispone un menor o mayor número de construcciones. En las manzanas se trabaja por bandas, cuya anchura crece con el fondo de las construcciones y con la aparición de los consiguientes patios de ventilación.

Hasta que no se domina, ya avanzado el siglo XIX, la solución de la casa en esquina, cuando dichas parcelas no hace falta que se ocupen con palacetes o villas singulares, no aparece la manzana con un gran patio central (Washington, Chicago, Barcelona). Al girar la banda se hace posible un uso más racional de la manzana.
En los ejemplos analizados empezamos a detectar una cierta contraposición de criterios, tipológicos e higiénicos, a veces; de aprovechamiento y económicos, o arquitectónicos, en otras ocasiones.

\section{Superficie del módulo}

La ambición del proyecto de fundación o de ensanche tiene en su ámbito total (superficie abarcada, número de manzanas) un indicador clave. Pero asimismo en el tamaño del módulo, relacionable además con una idea de gestión (división en lotes edificables, reparcelaciones), de capacidad de construir ciudad, del tipo de ciudad y de su uso.

Esto resulta evidente en las ambiciosas fundaciones españolas en Latinoamérica, o en la visión de Cerdà o del prefecto Hobrecht (por su notable anticipación). Pero es igualmente válido en sentido contrario, en el caso del Ensanche de Badalona de 1890 (por la modestia de sus objetivos).

Más adelante veremos como la medida del módulo se relaciona con el nivel de ocupación del suelo (mayor o menor nivel de privatización), con el carácter más público o más privado de cada trama (mayor o menor proporción de superficie destinada a calles).

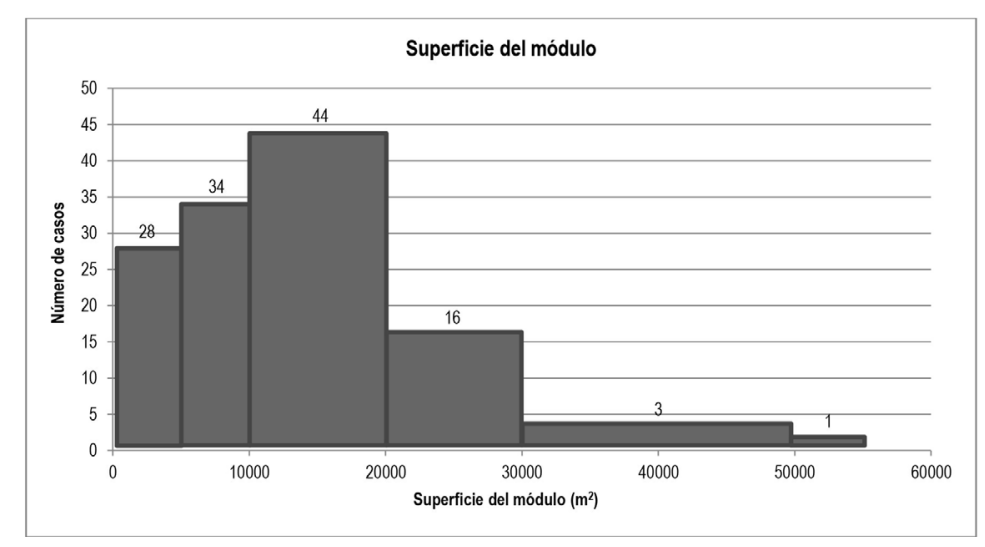

Pero si nos fijamos ahora en la tabla y los gráficos podemos observar una notable oscilación en cuanto al tamaño del módulo, desde 400 hasta casi 60.000 metros cuadrados (Berlín). La mitad de las propuestas tienen tamaños inferiores a una hectárea $\left(10.000 \mathrm{~m}^{2}\right.$, medida que supone, por ejemplo, manzanas cuadradas de 80 metros de lado y calles de 20 metros, o de 85 y 15 respectivamente); pero una de cada tres entre las estudiadas dobla dicho tamaño.

Hasta aproximadamente la mitad del siglo XIX podemos observar un lento pero continuo incremento del tamaño del módulo, que podemos atribuir a la mayor 
confianza en la capacidad de urbanizar, al crecimiento poblacional, y por ello, de la importancia de la ciudad. Pero asimismo encontramos proyectos tempranos que acometen una empresa urbanizadora de notable envergadura (la mayor parte de fundaciones coloniales en Latinoamérica y algunos ensanches).

El tamaño del módulo, con un incremento bien claro con el paso de los siglos, se estabiliza durante el primer tercio del siglo XIX; más bien empieza a descender. Muy pocas ciudades se plantean ya operaciones con módulos de más de $20.000 \mathrm{~m}^{2}$ (apenas Berlín, algunas ciudades del ferrocarril en California o en la epopeya colonizadora en la Provincia de Buenos Aires); incluso apreciamos una ligera disminución de esta medida. Más adelante veremos cómo los tamańos grandes tienen un notable nivel de privatización del suelo.

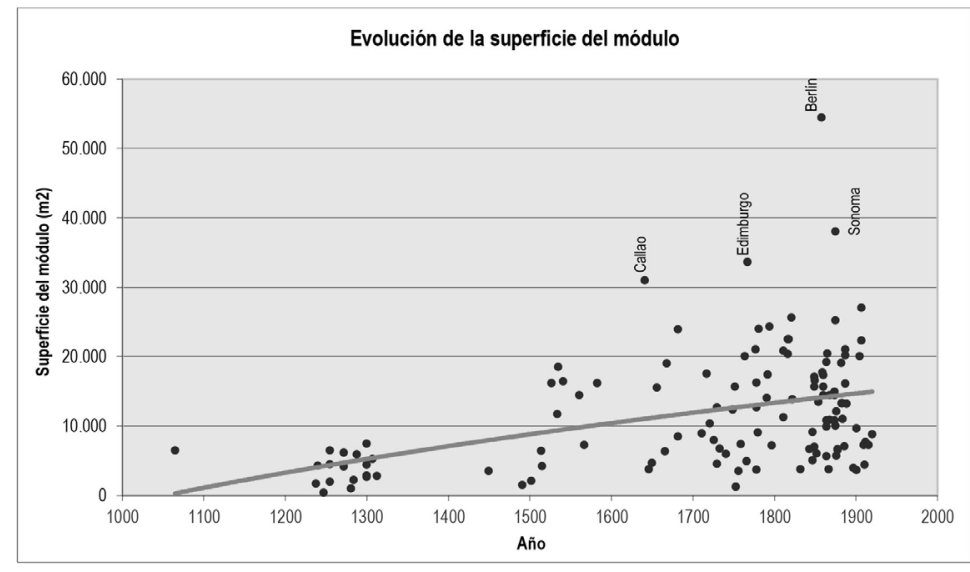

Adelantemos la valoración de algunos ejemplos. La Barceloneta con una calle de 6 metros, una profundidad inferior a 9 metros y un módulo de $1.200 \mathrm{~m}^{2}$, tiene un nivel de privacidad entre los más bajos; mientras que Lisboa (12 y 30 metros, $3.500 \mathrm{~m}^{2}$ ), tiene un nivel de privacidad aún reducido; y Buenos Aires $\left(22\right.$ y 105 metros, $16.000 \mathrm{~m}^{2}$ ), lo tiene muy elevado.

El análisis de las medidas de estos tres parámetros (ancho de la calle, profundidad de la manzana y superficie del módulo) permite asimismo preguntarnos si existen relaciones cruzadas entre los mismos, o discutir acerca de otras cualidades relevantes de estos proyectos (separación, oblongamiento, privatización, exposición), o incluso, si conocemos las reglas que rigen sus construcciones, evaluar en qué condiciones se produce un mayor aprovechamiento edificatorio. Veamos algunas relaciones entre los tres parámetros considerados.

\section{Relación entre la anchura de la calle y el fondo (lado menor) de la manzan a}

En principio ésta puede parecer una comparación absolutamente irrelevante, al tratarse de valores aparentemente independientes. Sin embargo al cruzar los datos descubrimos una estrecha relación. La profundidad de la manzana suele oscilar, salvo contadas excepciones, entre 3 y 7 veces la sección de la calle. Apenas un $5 \%$ están por debajo o por encima de dicha relación (bastidas, ciudades de la reconquista, o primeras ciudades coloniales en el primer caso; poblas, Manhattan y ensanches menores, en el segundo). Hay, por tanto, ejemplos singulares, que escapan de esta regla; Barceloneta, Mopanzier y Lisboa son muy generosas en cuanto al viario, y otras, como Gracia, Vilanova, o el conjunto de las poblas, muestran una proporción inferior a la media, y por debajo incluso de la relación que hemos encontrado.

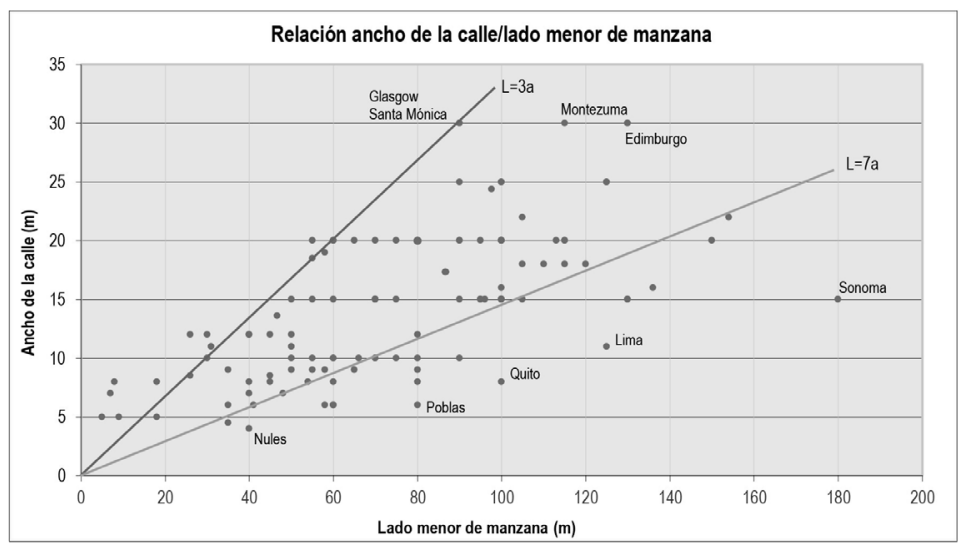

Observamos asimismo que cuanto más crece el fondo de la manzana, más se ajusta la dimensión de la calle, o dicho de otro modo se reduce la distorsión con respecto a la proporción que hemos observado.

Las distorsiones se concentran antes del siglo XVI, después apenas sobresalen por encima los casos de Manhattan, y algún ensanche menor, o por debajo, alguna ciudad colonial. Es decir la relación entre estos dos parámetros (anchura de la calle y fondo, o lado menor, de la manzana) se va ajustando con el paso del tiempo.

\section{Relación entre la anchura de la calle y la superficie del módulo}

Observamos que la relación entre ambos parámetros es incluso más contenida que la anterior, lo que resultaba previsible, toda vez que refleja un razonable ajuste entre el viario y el peso que éste soporta, entre espacio servidor y espacio servido. Este ajuste es más estrecho además al crecer el tamaño del módulo. 
También en este caso descubrimos excepciones: en Aix en Provence, Petra, Vilanova y Gracia, encontramos una dimensión excesiva de la superficie del módulo con respecto al viario; en el otro extremo, Edimburgo y Glasgow tienen una notable proporción de espacio viario, en relación con el de la manzana.

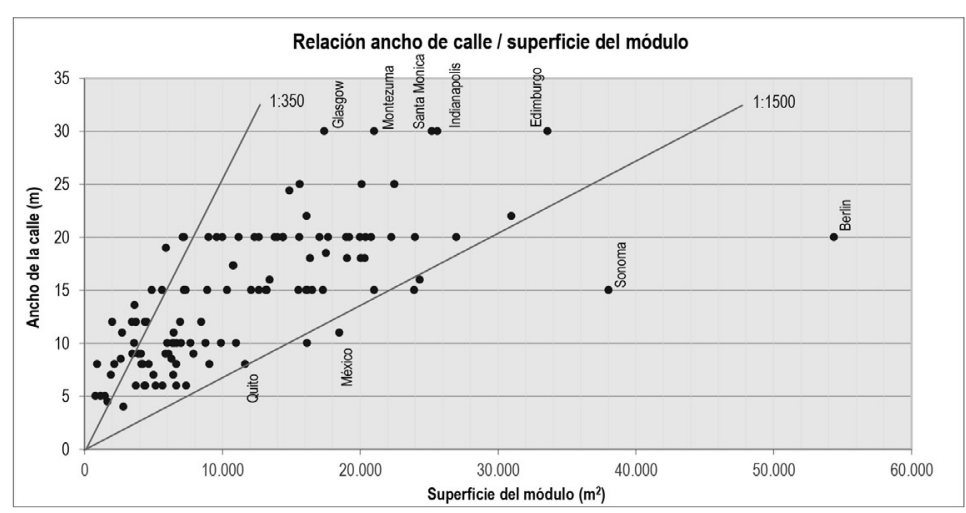

\section{Relación entre el lado menor de la manzana y la superficie del módulo}

Al cruzar los datos de estos dos parámetros descubrimos una relación bastante precisa. Seguramente ésta era de esperar, e incluso se puede considerar más que razonable desde la lógica de la geometría, pero es que además la curva a la que se ajusta dicha relación nos indica de hecho que estos proyectos (de fundación o de ensanche) tienden, al crecer el tamaño del módulo, a optar por manzanas cada vez más cuadradas.

En los casos con superficie del módulo más reducida los ejemplos se ajustan a la curva y la distorsión no resulta relevante (apenas algunas bastidas). Con el incremento del tamaño del módulo, y de manera más clara cuando supera una hectárea de superficie empiezan a aparecer casos que no se ajustan a la curva general. Son proyectos que, mayormente en los siglos XVIII y XIX, optan por soluciones muy poco "cuadradas". Entre éstos encontramos la propuesta de los Commissioners para Manhattan, con manzanas de 60 x 120 hasta 60 x 240 metros, y con calles y avenidas de entre 20 y 30 metros respectivamente; Friedrichstadt ( 80 x 170 y 20), Berlín ( 150 x 300 y 20), Edimburgo (130 x 180 y 30) o Filadelfia ( 130 x 150 y 15), así como otras muchas ciudades de América Central o del Norte. Podríamos considerar pues, que en general se tiende a buscar manzanas cada vez más cuadradas a medida que aumenta su tamaño, pero tan solo hasta alcanzar una cierta dimensión del módulo. A partir de dicho momento, continuar con manzanas cuadradas ya no resulta razonable, por disminuir el aprovechamiento, resultando o bien patios o bien profundidades edificables excesivas.
Si valoramos la evolución a lo largo del tiempo de dicha relación entre el lado menor de la manzana y la superficie del módulo, observaremos como el comportamiento de los diferentes casos se ajusta progresivamente a la ley (curva) que hemos encontrado.

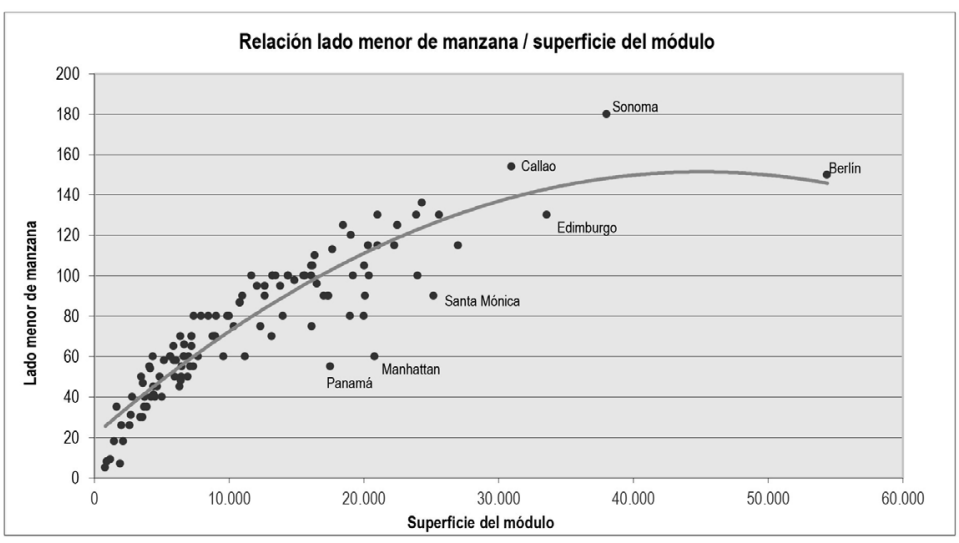

Una vez analizada la relación entre los tres parámetros procedemos a construir algunos criterios cruzados de evaluación. Hemos valorado en concreto los siguientes conceptos: oblongamiento, privatización y exposición.

Con el primero de ellos, oblongamiento, nos referimos a la cualidad "cuadrada" de las manzanas. Se trata de medir por tanto, lo que dista una manzana determinada de ser cuadrada (si lo fuera el valor de este concepto sería igua a 1). La fórmula aritmética del oblongamiento se expresa así: $\mathrm{Obl}=(1+\mathrm{a})^{2}$ / Mod (donde l es el lado menor o fondo de la manzana, a es el ancho de la calle y Mod la superficie del módulo).

Con el concepto de privatización queremos medir la proporción de espacio susceptible de ser edificado (generalmente privado) respecto del total, es decir, la relación entre la superficie ocupada por las manzanas y la total del módulo (añadiendo por tanto la que ocupan las calles, y, si fuera el caso, los espacios libres públicos). La fórmula aritmética de la privatización se expresa así: Pri $=(1+\mathrm{L}) /$ Mod. Si tuviéramos que expresarla utilizando solamente los tres parámetros analizados, sería Pri $=1 /(1+a)-\left(l^{*} a\right) /$ Mod $($ donde 1 es el lado menor o fondo de la manzana, L el lado mayor, a el ancho de la calle y Mod la superficie del módulo).

Con el concepto de exposición nos referimos a la longitud de fachada a la calle respecto a la superficie del módulo, al perímetro de fachada pública respecto a la unidad de intervención. La fórmula aritmética de la exposición 
se expresa así: $\operatorname{Exp}=(2 \mathrm{l}+2 \mathrm{~L}) /$ Mod. Si tuviéramos que expresarla utilizando solamente los tres parámetros analizados, sería $\operatorname{Exp}=\left(2 \mathrm{l}^{2}-2 \mathrm{a}^{2}+2 \mathrm{Mod}\right) /$ $(\operatorname{Mod} x(1+a) .8$

Finalmente, denominamos aprovechamiento (edificatorio) a la superficie edificable total sobre rasante de la manzana, dividida por la superficie del módulo.

\section{Oblongamiento}

El oblongamiento mide, de alguna manera, cuanto se acerca cada proyecto al ideal de la manzana cuadrada, y para ello mide la relación entre el lado menor del módulo (profundidad manzana más calle) y su superficie. ${ }^{9}$

Si la manzana (y por tanto el módulo) es cuadrada, el oblongamiento es igual a la unidad.

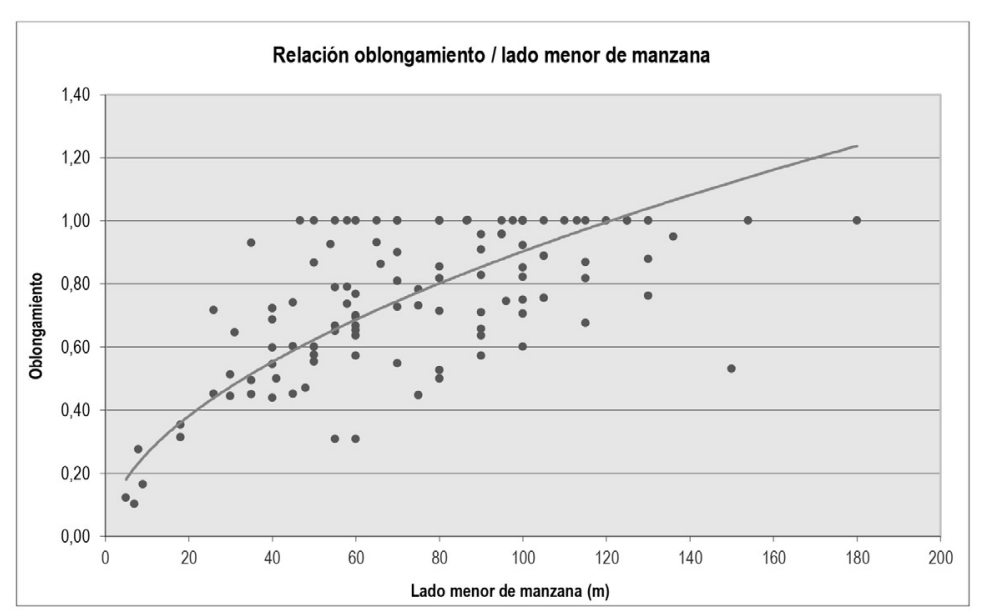

Si observamos el conjunto de los ejemplos considerados, veremos que el valor de este parámetro es muy bajo en manzanas muy desproporcionadas (muy largas y poco profundas), como en la Barceloneta $(0,15)$, Monpanzier $(0,30)$ y Aix en Provence $(0,45)$. Pero a medida que aumenta la profundidad de la manzana, ésta se va haciendo más cuadrada, como si persiguiera esa mayor regularidad. Existen algunas excepciones, como aquellas que son decididamente cuadradas desde el inicio (incluso algunas de pequeño tamaño). También podemos verificar que a partir de manzanas de 60 metros de profundidad se incrementa la dispersión del oblongamiento.

$8 \operatorname{Exp}=(21+2 \mathrm{~L}) / \operatorname{Mod}=(21 / \operatorname{Mod}+(2 \operatorname{Mod}) /(1+\mathrm{a})-2 \mathrm{a}) / \operatorname{Mod}=21 / \operatorname{Mod}+2 /(1+\mathrm{a})-2 \mathrm{a} / \operatorname{Mod}=2(1-\mathrm{a}) / \operatorname{Mod}$ $+2 /(1+a)=\left(21^{2}-2 a^{2}+2 \operatorname{Mod}\right) / \operatorname{Mod}(1+a)$

9 El lado menor del módulo equivale a la suma de la profundidad de la manzana y las dos semicalles, es decir $1+$ a
Como comentábamos antes, un comportamiento similar se observa en la relación entre el oblongamiento y la superficie del módulo. Con el incremento de su superficie los módulos, o sea las manzanas, tienden a hacerse cuadrados. Pero esto sucede solo hasta ciertos tamaños $\left(10.000 \mathrm{~m}^{2}\right)$. Por encima de dicha superficie, las manzanas vuelven a buscar proporciones más rectangulares, para garantizar un aprovechamiento más intenso del suelo.

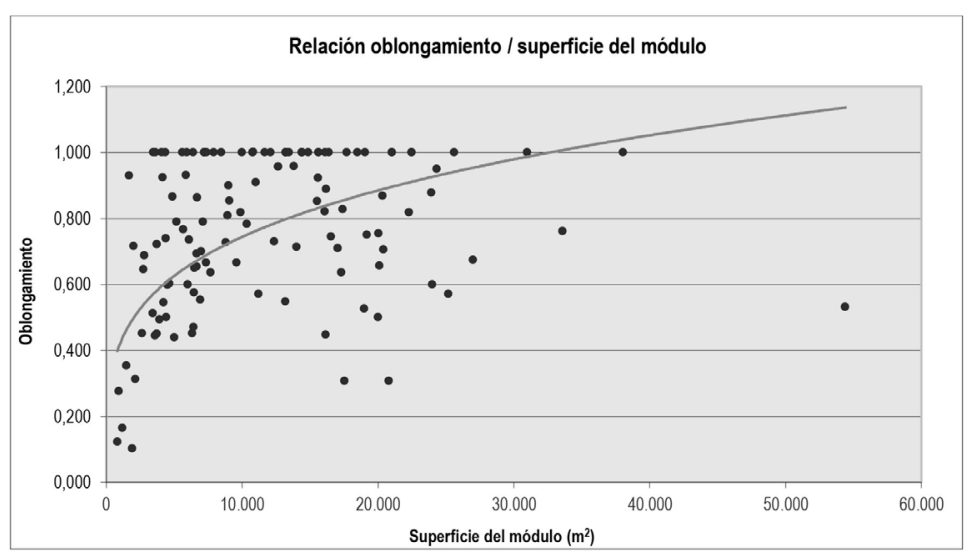

Con respecto a la evolución en el tiempo, observamos que las manzanas tienden a la cuadratura. Hasta 1800 esta tendencia es bien clara y acelerada. Cuadradas son además las manzanas en casi todas las ciudades de colonización en Hispanoamérica, o las de muchos proyectos que denominamos "de parcelación". Después de 1800 siguen habiendo proyectos con manzanas cuadradas, aunque en menor proporción. Son las que denominaremos retículas (proyectos que acentúan los cruces, y que disponen de grandes patios centrales). Pero por lo general los proyectos se mantienen con valores entre 0,5 y 0,75 de oblongamiento.

\section{Privatización}

La privatización mide la proporción de suelo privado, la parte edificable (la manzana) del módulo. Podríamos decir que su inversa mide la proporción de viario por módulo, y nos ofrece por tanto una cierta idea de su capacidad de servicio.

Salvo excepciones muy puntuales los proyectos analizados muestran valores de privatización entre 0,45 y 0,85 . Los primeros son proyectos más públicos (algunas bastidas, como Carcassone y Mirande, o ciudades de fundación en Latinoamérica, como Santo Domingo, Guadalajara, Santa Fe de Bogotá, pero asimismo Glasgow y el proyecto de Otto Wagner para Viena), con proporciones muy altas (alrededor de la mitad) de su superficie destinada 
a viario. Esto explica que hayan permitido aprovechamientos edificatorios bien notables. En el otro extremo encontraremos una veintena de proyectos bien cicateros en cuanto al viario, como algunas ciudades norteamericanas, pero asimismo fundaciones en Latinoamérica y otros tejidos urbanos en Espańa. Así Gracia, Vilanova, Petra o Lima, tienen una proporción de viario respecto del módulo que disminuye hasta el 15\%, lo que explica, al contrario que en el caso anterior, que sean tramas con dificultades para evitar el colapso circulatorio, que no soportan bien intensificaciones de su aprovechamiento edificatorio.

Si ahora analizamos la relación entre la profundidad de la manzana y la privatización, observaremos que, excepto casos singulares, las profundidades más pequeñas dan valores mucho más bajos de privatización, y que al aumentar la profundidad, la privatización oscila entre 0,6 y 0,8 , ajustándose progresivamente a 0,7 .

Con respecto al módulo, en tamaños pequeños encontramos una notable oscilación, con valores desde 0,55 hasta 0,85 . En tamaños medianos y grandes se reduce dicha dispersión. El suelo privado oscila entonces entre $2 / 3$ y $3 / 4$ del módulo.

Con el paso del tiempo, y especialmente con los grandes ensanches decimonónicos, los proyectos disminuyen el valor de la privatización. Se es consciente de la necesidad de amplias calles y avenidas para dar soporte a una ciudad con edificaciones cada vez más importantes.

Merece la pena comparar hasta qué punto proyectos con manzanas tan similares alcanzan valores tan diferenciados. Así si comparamos los casos de Gracia (manzana tipo de 60 metros de lado y calle de 6 metros), San Sebastián (60 y 15 metros respectivamente) y Viena (65 y 20 metros respectivamente) veremos que los valores de privatización alcanzados descienden desde 0,85 a 0,64 y a 0,58, lo que explica el carácter más desahogado de algunas tramas recientes. Como veremos enseguida, esto va acompañado de una mayor exposición, es decir, de mejores condiciones para su arquitectura.

\section{Exposición}

La exposición viene a representar la proporción de longitud de fachada a la calle por superficie del módulo, lo que presupone una cierta garantía de urbanidad, así como claras ventajas para la arquitectura.

La exposición oscila entre valores muy altos (los de Carcasonne, Barceloneta, Mirande, Santa Fe, Almenara, Monpanzier, Lisboa, Aix en Provence), llegando hasta 0,2 y muy bajos (casos como Filadelfia, Valencia, Los
Ángeles, Nueva Orleans, Santa Mónica, El Callao, Edimburgo y Berín), llegando hasta 0,017 , es decir 12 veces más. Cabe aclarar que en manzanas de gran tamańo con un generoso patio central, como es el caso de Barcelona, tendríamos que considerar las fachadas al mismo, con lo que se incrementaría muy notablemente el valor de la exposición, la cantidad en definitiva de fachadas dando al exterior (ya sea a la calle o a patios centrales de dimensiones generosas).

En todo caso es interesante constatar como los proyectos del barroco incrementan el valor de la exposición, favorecen la fachada, buscan exponer la arquitectura. En cambio, muchas ciudades fundadas en Estados Unidos o los grandes ensanches del XIX dan los valores más bajos (aunque en estos casos cabe plantear la salvedad comentada, de las fachadas al patio interior).

Descubrimos que cuanto más crece el módulo, más baja la exposición, y que lo hace siguiendo una curva muy precisa, una relación inversa cuadrada (por razones geométricas esta relación era esperable). De hecho cuando crece el perímetro de la manzana (y por tanto, del módulo) se incrementa en proporción cuadrada su superficie; ${ }^{10}$ con lo cual la exposición tiende a decrecer, a menos de que el ancho de la calle distorsione dicha relación (y ya vimos que no era así, ya que ésta suele oscilar entre 5 y 30 metros).

Idéntica ley se puede verificar al comparar exposición y profundidad de la manzana (o del módulo), aunque aquí la correlación es algo menos estricta. La razón estriba en que al aumentar mucho la profundidad de la manzana, el lado largo de la misma no lo hace proporcionalmente (recordemos que entonces las manzanas tendían a la cuadratura).

No se puede apreciar un cambio significativo de la exposición a lo largo del tiempo, más allá de un incremento claro, aunque con numerosos altibajos, a partir del siglo XVI. Si bien el barroco "busca fachada", también lo hacen proyectos muy posteriores.

Veamos cómo se comportan en este sentido algunos ejemplos. En Edimburgo John Craig propone en 1767 unas manzanas de tamaño considerable, 130 x 180 metros, con un cuerpo bajo a ambos lados de una calle de servicio que divide la manzana en dos. Esto da lugar a una privacidad media $(0,70)$ y a una exposición relativamente reducida $(0,018)$, aunque de nuevo aquí habrá que considerar el valor de la fachada al interior de la manzana. Por otro lado la altura relativamente moderada y la escasa profundidad, da lugar asimismo a unos valores muy bajos de aprovechamiento $\left(0,44 \mathrm{~m}^{2}\right.$ de techo por $\mathrm{m}^{2}$ de suelo). Estas características se corre- 
girán años después, en la siguiente extensión de la ciudad, en la extensión alrededor de Moray Place, que adopta una morfología suburbana.

La propuesta de los Commissioners en Manhattan en 1811 (de 120 o 240 hasta 60 metros) dan lugar a una trama mucho más pública $(0,64)$ y casi al doble de exposición $(0,032)$, aun así muy reducida. Las alturas y profundidades, ilimitadas al inicio y considerables después de la Zoning Ordinance de 1916, dan lugar a un altísimo aprovechamiento.

Las manzanas de Berlín (entre 80 x 170 y 150 x 300 metros) dan lugar a tramas muy poco públicas (entre 0,72 y 0,82 ) y con una exposición muy baja (entre 0,026 y 0,016 ). Entre otras razones esto está a la base de las considerables críticas a la propuesta de Hobrecht (con las conocidas Mietkasernen). Numerosas alternativas a finales de siglo pretenden precisamente corregir estos valores en la trama de Berlín.

\section{Aprovechamiento}

La medida del aprovechamiento (edificatorio) resulta menos sencilla de evaluar que los parámetros anteriores, dado el carácter cambiante de las ordenanzas, de las reglas que limitan altura y profundidad de las construcciones. Los cálculos que hemos realizado se refieren por ello a los valores atribuidos a las primeras construcciones, ya sean del proyecto original, o bien de una etapa consolidada de la ciudad, pero previa a los procesos de substitución edificatoria y densificación recientes.

Es por ello que los datos evaluados no cubren la totalidad de los proyectos, sino aquellos en que podemos identificar una ordenanza de un periodo claramente representativo. Aun así podemos deducir algunas conclusiones interesantes.

El aprovechamiento ha tendido a disminuir a medida que aumenta el lado menor del rectángulo. La explicación radica en que no permite un aprovechamiento tan intensivo (aparecen patios muy grandes o una ocupación extensiva de las manzanas). El aprovechamiento ha tendido a disminuir, por idénticas razones, con el incremento del tamańo del módulo. La evolución a lo largo del tiempo del aprovechamiento no sigue una pauta clara. Los valores algo más altos son si acaso fruto de las mayores alturas alcanzadas con la substitución de los edificios previos en el siglo XIX.

\section{A modo de conclusiones}

La principal conclusión y la única realmente rotunda, pero no por ello menos interesante, es que no existen medidas mágicas en el proyecto de las tramas urbanas, aquellas que aseguren las condiciones más adecuadas a su arquitectura, a la circulación en sus calles y a la habitabilidad de sus viviendas.

Pero aun así, hemos podido verificar como las cuadrículas de tamaño mediano ofrecen una menor privacidad, o sea, una mayor proporción de viario (y generalmente, y por ello, de urbanidad), y una mejor exposición. Hablamos de tamańos de módulo de unos $10.000 \mathrm{~m}^{2}$, o sea por ejemplo, manzanas cuadradas de 80 o 85 metros de lado y calles de 20 o 15 metros de ancho.

Sin embargo, tal y como apunta Manuel de Solà en su carta a Leon Krier ${ }^{11}$, hay otro aspecto bien remarcable y es que el estudio de las dimensiones básicas de este amplio grupo de proyectos, nos permite distinguir lo que significan tramas (fundaciones, extensiones o ensanches) bastante diferentes. Y así se pueden reconocer claramente tres familias.

a) Aquellas pensadas de hecho como "bandas edificadas", donde domina la idea de parcelación.

Excepto Edimburgo serían las de menores tamaños de módulo, con lo que resultan bastante generosas en viario (poco privatizadoras), presentando profundidades de manzana no muy grandes (lo que supone manzanas alargadas) y valores de exposición considerables. Aquí incluiríamos, por ejemplo, proyectos como los de la Barceloneta, Montpanzier, Aix Provence, Lisboa, Manhattan y Edimburgo.

b) "Las cuadrículas" ocupadas densamente, donde predomina una idea de manzana ocupada totalmente, con patios.

Incluye desde tamaños pequeños a medianos de módulo, e incluso alguno grande. Suelen presentar manzanas generalmente cuadradas, con valores bajos de exposición y escasa proporción dedicada a calles. Aquí podemos referirnos a proyectos medievales y barrocos, y a la mayor parte de las ciudades de fundación latinoamericanas (con cuadras ocupadas intensamente). Cabe destacar los proyectos de Aranjuez, Trieste, Bari, Turín, Milán, Caracas, Buenos Aires, Santiago de Chile, Berlín y su previa extensión de la Friedrichstadt.

c) Por último tenemos las que denominamos "retículas", aquellas ciudades que enfatizan los cruces, donde domina la idea de arquitectura. 
Son proyectos que buscan mayores superficies de módulo, lo que suele implicar la aparición de un patio central de gran tamańo, y la necesidad de afrontar la solución, nada sencilla al inicio, de la casa en esquina. Tienen por lo general una baja exposición (no tanto si consideráramos la amplitud, y calidad en el caso de Barcelona, de las fachadas al patio central). Muestran valores intermedios de privatización, garantizando por lo general un adecuado soporte del viario, y muchas tienden a enfatizar, incluso achaflanándolo) el cruce, con lo que se ofrece un magnífico escenario para la nueva arquitectura. Cabe destacar en este grupo los proyectos de Stuttgart, San Sebastián, Lyon, Chicago, Washington, Madrid, Atenas, Viena y Barcelona.

Importa remarcar para concluir, después de medir cuidadosamente tantos proyectos, que estas dimensiones no tienen valor en sí mismas, sino en tanto que nos informan acerca de una idea de arquitectura, una idea de calle y una idea de ciudad. Y es en este sentido que en el éxito del proyecto tiene tanta importancia, como en cualquier diseño, una adecuada combinación de todas las medidas.

\section{Bibliografía}

Alomar Esteve, Gabriel, Urbanismo regional en la Edad Media: Las "Ordinacions" de Jaime II (1300) en el Reino de Mallorca. Gustavo Gili, Barcelona, 1976.

AA.VV. La Ciudad Hispanoamericana. El Sueño de un orden. Centro de Estudios Históricos de Obras Públicas y Urbanismo, Ministerio de Fomento. Madrid, 1977.

Pesoa Marcilla, Melisa, "Una ciudad para la Pampa. Idea, técnica, proyecto y construcción de las ciudades de la provincia de Buenos Aires durante el siglo XIX", tesina del Master de investigación en Urbanismo. Universidad Politécnica de Cataluña, Barcelona, 2012

Solà-Morales, Manuel, "Querido León, ¿por qué 22 × 22 ?", en Arquitecturas Bis, número 20, paginas $7-12,1978$ 